behaviour that science can provide. One might well prefer an account that better shows how our rational nature is integrated with our biological and physical natures. Nonetheless, this is a rich and provocative work. It is well worth the time and attention of anyone working in these areas.

SARA WORLEY

Bowling Green State University Bowling Green, OH 43403 USA sworley@bgsu.edu

\title{
References
}

Aguirre, B.F., D. Wenger, and G. Vigo. 1998. A test of the emergent norm theory of collective behavior. Sociological Forum 13: 301-20.

Latane, B. and S. Nida. 1981. Ten years of research on group size and helping. Psychological Bulletin 89: 308-29.

\section{Phenomenal Consciousness: Understanding the Relation Between Experience and Neural Processes in the Brain}

\author{
By Dimitris Platchias
}

Acumen, 2011. viii +216 pp. $£ 55.00$ cloth, $£ 18.99$ paperback

Is phenomenal consciousness susceptible to scientific investigation? Pessimists think it isn't partly on the grounds that phenomenal consciousness consists in the presence of qualia. Qualia are ways things seem to a subject (Block 1994: 210-1). The way scarlet looks, the way Middle C sounds, the way pain feels - each is an example of a distinct quale. According to pessimists, ways things seem are essentially conscious and, hence, subjective: for there to be a way things seem to a subject in mental state $S$ just is for there to be something it's like for that subject to be in S. And, in order to know that this (inwardly demonstrating a particular quale) is what it is like to be in S, one has to occupy a specific point of view. But, in order for something to be susceptible to scientific investigation, it has to be open to observation and knowledge from many different points of view. In other words, only objective phenomena are proper subjects of scientific inquiry (Nagel 1974). So it appears there can't be a science of phenomenal consciousness.

Dimitris Platchias is an optimist. In his book, Phenomenal Consciousness: Understanding the Relation Between Experience and Neural Processes in the Brain, Platchias sets himself the task of defending optimism by arguing for two central theses - one negative, the other positive. The negative thesis is that qualia aren't essentially subjective (64-6). Some mental states, according to Platchias, are such that (i) qualia accompany them, but (ii) there isn't anything it's like for the subject to be in them. Furthermore, Platchias thinks that some mental states are such that (iii) qualia fail to accompany them, but (iv) there is something it's like for the subject to be in them. 
Platchias concludes that it's not in virtue of the presence of qualia that a mental state is conscious (it's not in virtue of there being a way things seem when one occupies a mental state that there's something it's like for one to be in that state). What is it, then, in virtue of which some mental states are conscious? The positive thesis addresses this question. A subject's state, $\mathrm{S}$, is conscious (there's something it's like for the subject to be in S) in virtue of an 'unmediated', occurrent higher-order thought that she's in S (159-63). Platchias calls this thesis 'higher-order representationalism'. If true, then consciousness is a kind of cognition - a phenomenon for which we have a young but flourishing science.

Phenomenal Consciousness consists of six chapters. We start off in Chapter 1 with a survey of introductory material in the philosophy of mind. Chapters 2 and 3 defend the negative thesis. Chapter 4 criticizes 'first-order representationalism' - Platchias's label for the doctrine that $S$ is conscious in virtue of being disposed to bring about a higher-order thought that one is in S. Chapter 5 discusses the 'explanatory gap'. Chapter 6 provides a defence of the positive thesis.

I want to focus my comments on Chapters 2 and 3.

Platchias invites us to consider blindsight - a condition in which a subject is able to visually gather information about her surroundings with no sign of conscious visual awareness. According to Platchias, the visual state of a blindseer satisfies (i) and (ii); qualia accompany the subject's visual state, but there isn't anything it's like for the blindseer to be in that state (66-71). Setting aside the possibility that blindseers really are visually aware, but that the awareness isn't accessible to faculties involved in verbalization (a possibility that Platchias discusses (75-8)), the case of blindsight does very little to motivate the negative thesis. It's not at all clear that the visual state of a blindseer satisfies (i). It's not at all clear, in other words, that there's a way things look to a subject for whom there isn't anything it's like to see.

Platchias provides another example in support of his negative thesis (60-4). Jacques, let's say, is a monoglot Frenchman. Jack is a monoglot Englishman. So, Platchias says, when they hear someone utter the sentence 'Londres est jolie' Jacques is going to have an experience that Jack isn't. Jacques, but not Jack, is going to experience understanding the utterance. There's something it's like for Jacques to hear 'Londres est jolie', and there's something it's like for Jack to hear the very same utterance, but what it's like for Jacques will differ from what it's like for Jack. Does the difference in what it's like for the two subjects consist in a difference between the qualia that accompany each auditory state? Platchias thinks not, because both Jacques and Jack heard the same pattern of sounds. So, according to Platchias, the way things auditorily seem to Jacques just is the way things auditorily seem to Jack. But since there's a difference in what it's like for the two subjects without a corresponding difference in the way things seem to them, what things are like (consciousness) mustn't consist in the way things seem (qualia).

As the case is set up, Jacques and Jack hear the same pattern of sounds. But it doesn't follow that the way things auditorily seem to one is the way things auditorily seem to the other. In addition to hearing a particular sequence of sounds, Jacques, but not Jack, heard that London is pretty. And one might think this difference in what Jacques and Jack heard suffices to bring about a difference between the way things auditorily seem to them. More could be said about this case, but space is limited. 
In passing, Platchias offers a conceivability argument for his negative thesis. It's conceivable, he says, that there be conscious mental states without qualia, and that there be unconscious mental states with qualia. So, Platchias concludes, it must be possible that there be such states (62). (Is it really conceivable in the abstract that there be something it's like for a subject without there being a corresponding way things seem to her, or that there be a way things seem to a subject without there being something it's like for her? Without a concrete example to motivate this premise, it's unlikely to put pressure on pessimists. And, as we've seen, none of the principal examples are convincing.) The argumentative strategy here is a bit puzzling, since fewer than thirty pages earlier Platchias rejects the conceivability argument for dualism on the grounds that 'the fact that a situation is conceivable does not mean that it is a genuine possibility' (37). Platchias complains that we currently lack a principled method, or 'criterion', for distinguishing good from bad conceivability arguments. (Platchias fails to engage with the hundreds of pages that David Chalmers has written providing such criteria.) Without a criterion to vindicate the dualist's conceivability argument, Platchias thinks it would be hasty to accept her doctrine on the basis of such considerations. What assurance, then, does Platchias take there to be for thinking that his conceivability argument is a good one? He provides no principle to vindicate his use of conceivability.

Phenomenal Consciousness is a challenging book, in part because it grapples with challenging problems, but also because the discussion is at times confusing. I'm no more optimistic about the prospects for a science of consciousness than I was before reading it.

\author{
Mahrad Almotahari \\ Birkbeck, University of London \\ Malet Street, London WC1 E7HX, UK \\ m.almotahari@bbk.ac.uk
}

\title{
References
}

Block, N. 1994. Consciousness. In A Companion to the Philosophy of Mind, ed. S. Guttenplan, Oxford: Blackwell.

Nagel, T. 1974. What is it like to be a bat? Philosophical Review 83: 435-50.

\section{Making Sense of Freedom and Responsibility}

\author{
By Dana Kay Nelkin \\ Oxford University Press, 2011. xii +194 pp. $£ 30.00$
}

What must the world be like, and what must we agents be like, in order to be morally responsible for our actions? In Making Sense of Freedom and Responsibility, Dana Nelkin develops and defends what she dubs the 'rational abilities' view (RA) of moral responsibility. On this compatibilist view, an agent is morally responsible for an 